\title{
Evaluation of the biosorption potential of Aspergillus flavus biomass for removal of chromium (VI) from an aqueous solution
}

\author{
Riti Thapar Kapoor \\ Amity Institute of Biotechnology, Amity University, Noida - 201 313, India.
}

\begin{tabular}{l}
\hline ARTICLE INFO \\
\hline Article history: \\
Received on: July 21, 2021 \\
Accepted on: October 08, 2021 \\
Available Online: February 15, 2022 \\
\hline
\end{tabular}

Key words:

Aspergillus flavus, biomass, biosorbent, chromium

\begin{abstract}
Chromium biosorption potential of live and dead biomass of Aspergillus flavus was analyzed by batch experiments under various experimental conditions like $\mathrm{pH}$, adsorbent dose, exposure period, and temperature. Maximum biosorption of hexavalent chromium was observed at $\mathrm{pH} 3.5$ with adsorbent dose $2.5 \mathrm{~g}$ at $30^{\circ} \mathrm{C}$. Three days were considered as the optimum exposure period for chromium removal for live biomass, whereas 1.3 hours exposure period for dead biomass of A. flavus. The equilibrium data were examined by Langmuir and Freundlich isotherms. Freundlich isotherm appeared to be the best fit model. Phytotoxicity test was conducted to check the effect of the treated chromium solution on the seed germination, seedling length, and vigor index of Vigna radiata. Only $23 \%$ germination was reported in chromium metal-treated $V$. radiata seeds, but germination and growth parameters of mung bean seeds were significantly increased in the chromium solution after treatment with dead and live biomass. The chromium biosorption potential showed the following trend: dead A. flavus > live A. flavus. Hence, live and dead biomass of A. flavus can be applied as a safe and economically feasible biosorbent for hexavalent chromium elimination for the treatment of industrial effluent or wastewater system.
\end{abstract}

\section{INTRODUCTION}

Heavy metal pollution in terrestrial and aquatic ecosystems is a major threat. Heavy metals have atomic numbers more than 20 and a density $>5 \mathrm{~g} / \mathrm{cm}^{3}[1]$. They have become a serious threat due to their long-term endurance, toxic and non-degradable nature with a negative impact on human health after entering into the food chain [2]. They interact with organic compounds and transform them into more complicated toxic complexes [3,4]. The heavy metals cannot be removed after they enter in the organs of human beings as they cumulate, which may cause changes in biochemical processes and may lead to chronic and long-term hazardous effects [4]. The presence of a high concentration of chromium in the soil and water due to excessive release from industrial activities has become a serious issue [5]. The hexavalent chromium [Cr (VI)] is released into the environment from various industrial processes such as electroplating, dye, paint, leather, metal finishing, steel, and

*Corresponding Author

Riti Thapar Kapoor, Amity Institute of Biotechnology, Amity University,

Noida-201313,India.E-mail: rkapoor@amity.edu paper production work [6,7]. It has seven oxidation states in which chromite [Cr (III)] and chromate [Cr (VI)] states are durable natural forms of chromium [8]. Chromium (VI) is an oxidizing agent and its soluble nature and bioavailability converts it into a toxic form of chromium [9]. The International Agency for Research on Cancer has kept chromium under the category of group one carcinogens [10]. The hexavalent chromium in the environment mainly occurs as chromate oxyanions which act as strong mutagen and oxidizing agent [11]. The chromate oxyanions are similar to the sulfate oxyanions and enter in the cells with the help of sulfate transporters available on the cell surfaces [12]. Under normal physiological conditions, hexavalent chromium crosses the cell membrane and reacts with ascorbate and glutathione and generates free radicals, and finally gets converted into trivalent chromium which is stable in nature [13]. The reduction of glutathione produces reactive oxygen species which can damage biomolecules such as sugar, protein, lipid, and nucleic acids [12]. Chromium can show alterations in DNA methylation and histone modification in cells [14].

However, removal of chromium from industrial effluents is an arduous task. Different methods such as ion exchange, evaporation, 
membrane separation, electrochemical treatment, and chemical reduction have been applied for chromium removal from contaminated effluents [15]. All the above mentioned conventional methods are expensive and time-consuming. Hence, there is a need to explore simple, cost-effective, and environmental benign approaches for the elimination of chromium from wastewater. Biosorption is a physicochemical process that utilizes biomass for the removal of heavy metals from aqueous solution [16]. Fungi have an excellent binding ability for heavy metal ions and can be employed as biosorbent. The metal ion binding ability is due to the high electronegativity present on the surface of fungal biomass which can attract and sequester metal ions $[17,18]$. The dead biomass of microbes can also be used for the recovery of metal ions as it binds metal ions more efficiently [19]. As compared to traditional ways, biosorption has been considered as a cost-effective, ecofriendly, and efficient method to solve the problem of environmental pollution which rose due to heavy metals with regeneration of the biosorbent, recovery of metals, and less sludge formation [20]. Very few reports are available on the application of dead biomass for metal biosorption. To the best of our knowledge, no information is available till date to study the effect of live and dead biomass of Aspergillus flavus on the removal of chromium from aqueous solution and effect of treated metal solution on mung bean seeds. Therefore, the present investigation was carried out to analyze live and dead biomass of $A$. flavus ability for chromium removal from aqueous solution under different environmental conditions.

\section{MATERIALS AND METHODS}

\subsection{Maintenance of the Fungal Biomass}

Aspergillus flavus was isolated from the soil samples. The isolated fungi were maintained on the potato dextrose agar medium. Cultures were kept at $4^{\circ} \mathrm{C}$ and sub-cultured in every 15 days. The inoculated slants were incubated for 7 days at $28^{\circ} \mathrm{C} \pm 2^{\circ} \mathrm{C}$.

\subsection{Growth Conditions}

One disk of fungal biomass ( $4 \mathrm{~mm}$ diameter) was inoculated into modified Czapek's Dox medium (sucrose $=30 \mathrm{~g}, \mathrm{NaNO}_{3}=2 \mathrm{~g}$, $\mathrm{K}_{2} \mathrm{HPO}_{4}=1 \mathrm{~g}, \mathrm{MgSO}_{4} .7 \mathrm{H}_{2} \mathrm{O}=0.5 \mathrm{~g}, \mathrm{KCl}=0.5 \mathrm{~g}$, and ferrous sulfate traces) at $\mathrm{pH} 6.9$. Flasks were incubated for 7 days at $29^{\circ} \mathrm{C}$ $\pm 2{ }^{\circ} \mathrm{C}$. By filtration, fungal biomass was separated from culture, washed with autoclaved distilled water, and dried with filter papers to get biosorbent [21].

\subsection{Preparation of Dead Fungal Biomass}

The live biomass of A. flavus was converted into dead biomass by boiling it in $0.5 \mathrm{~N} \mathrm{NaOH}$ solution for 15 minutes, washed with double distilled water till the $\mathrm{pH}$ becomes 7 . Biomass was dehydrated at $5^{\circ} \mathrm{C}$ for 1 day and powdered [22]. Dead biomass was kept in a desiccator for further use. It was observed that approximately $4 \mathrm{~g}$ of live biomass (wet weight) was equivalent to $0.35 \mathrm{~g}$ of dead biomass of $A$. flavus.

\subsection{Removal of Chromium by A. flavus}

Hexavalent chromium (10 mg/l) was prepared by mixing of potassium chromate in sterilized distilled water which was further used to prepare required concentrations. Aspergillus flavus live or dead biomass was mixed in a metal solution $(100 \mathrm{ml})$ in different conical flasks and the metal solution without any live or dead biomass was treated as control. Factors that affect chromium biosorption by fungal biomass were investigated under different experimental conditions. In order to study the effect of exposure time for maximum adsorption of $\mathrm{Cr}$ (VI), several equilibrium experiments were conducted at different time period ranging from 0.5 to 96 hours. The effect of $\mathrm{pH}(1-5)$ on chromium removal was carried out by maintaining desired $\mathrm{pH}$ with $\mathrm{NaOH}$ or $\mathrm{HCl}$ before mixing biomass. The dependence of chromium uptake on initial chromium concentration was also analyzed by increasing chromium concentration from 20 to $120 \mathrm{mg} / \mathrm{l}$. The effect of different fungal biomass dosages (0.5-3.5 g live and dead biomass respectively) on the $\mathrm{Cr}$ (VI) uptake was also studied. The effect of temperature $\left(10^{\circ} \mathrm{C}-50^{\circ} \mathrm{C}\right)$ was also investigated on the chromium removal. The flasks were kept in a shaking incubator under different experimental conditions for the optimization of various parameters. At the end of the experiment, the supernatant was used for residual metal analysis [23].

\subsection{Chromium Biosorption Capacity}

Chromium content was analyzed after the formation of colored compound of chromium with 1,5-diphenylcarbazide and optical density was measured at $540 \mathrm{~nm}$ with a spectrophotometer [24]. Biosorption of chromium shows the uptake of metal and it was assessed by the following equation:

$$
q_{\mathrm{e}}=\left(C_{\mathrm{i}}-C_{\mathrm{e}}\right) V / m
$$

where $q_{\mathrm{e}}=$ equilibrium, $V=$ volume of hexavalent chromium, $C$ and $C_{\mathrm{e}}$ are initial and final concentrations of hexavalent chromium metal, and $m=$ biosorbent mass.

\subsection{Adsorption Isotherm}

Two isotherm models were used to interpret sorption equilibrium in the present study. Different concentrations of chromium metal solution (20-120 mg/l) were treated with different adsorbent doses of $A$. flavus. The adsorption capacity and equilibrium solution concentrations were evaluated with suitability of the isotherm.

\subsubsection{Langmuir isotherm}

The Langmuir isotherm model speculates that adsorption process takes place in monolayer mode [25].

Langmuir equation was expressed as follows:

$$
C_{\mathrm{e}} / q_{\mathrm{e}}=1 / q_{\mathrm{e}} K_{1}+C_{\mathrm{e}} / q_{\mathrm{m}}
$$

$q_{\mathrm{e}}(\mathrm{mg} / \mathrm{g})=$ chromium metal adsorbed at equilibrium, $q_{\mathrm{m}}(\mathrm{mg} / \mathrm{g})=$ chromium metal adsorbed, $C_{\mathrm{e}}$ is equilibrium chromium concentration (mg/l), and $K_{1}$ is Langmuir constant associated with binding capacity of chromium on fungal biomass.

\subsubsection{Freundlich isotherm}

Freundlich isotherm explains the distribution of solute molecules between aqueous and solid phases at equilibrium. This isotherm 
assumes an exponential disparity in energy of surface-active sorption site and reduction in adsorption heat is logarithmic [26].

The Freundlich equation is as follows:

$$
\log q_{\mathrm{e}}=\log K_{\mathrm{f}}+1 / n \log C_{\mathrm{e}}
$$

Freundlich constants, such as $K_{\mathrm{f}}$ and $\mathrm{n}$, are adsorption capacity and adsorption intensity, respectively. Nature of process $(n)$ may be: $n=1$, a linear process; $n<1$, a chemical process; and $n>1$, a physical phenomenon.

\subsection{Phytotoxicity Study}

The effect of chromium before and after treatment with live and dead biomass of $A$. flavus was studied on the growth parameters of mung bean (Vigna radiata) seeds.

\subsubsection{Seed germination test}

Mung bean ( $V$. radiata var. KM2195) seeds were thoroughly washed with tap water to remove dust then sterilized with distilled water / $\mathrm{NaOCl}(10: 1)$ solution for 5 minutes and washed four to five times again with autoclaved distilled water. Seeds of mung bean were immersed in chromium solution before and after A. flavus live and dead biomass treatment for 4 hours. Filter paper was placed on sterilized petri dishes and control and treated mung bean seeds were transferred into petri dishes. The petri dishes were covered with sterilized polythene bags and kept in a seed germinator for a week under $80 \%$ relative humidity at $25^{\circ} \mathrm{C} \pm 2^{\circ} \mathrm{C}$ with 12 hours light following the ISTA guidelines [27].

The total number of seeds germinated was calculated using the following formula:

Germination percentage $=$ Total number of seeds germinated / Total number of seeds taken for germination $\times 100$

\subsubsection{Seedling length}

The radicle and plumule length of mung bean seedlings were measured with a measuring scale.

\subsubsection{Vigor index}

The vigor index was calculated as follows:

Vigour index $=$ Total seedling length $(\mathrm{mm}) \times$ percentage of germination [28].

\subsection{Statistical Analysis}

Treatments were exhibited as randomized block design with three replications. Data were statistically analyzed using analysis of variance by using SPSS software (version 16 SPSS, US).

\section{RESULTS AND DISCUSSION}

To identify suitable conditions for chromium elimination, comparative analysis of live and dead biomass of A. flavus was carried out by changing various parameters like exposure time, $\mathrm{pH}$, chromium amount, temperature, and adsorbent dose through the batch experiments.

\subsection{Effect of Exposure Time}

Batch experiments were conducted to investigate A. flavus live and dead biomass effect on chromium removal under different exposure periods. The results showed that the biosorption capacity was increased rapidly with increasing contact time (Figs. 1 and 2). The 72 hours was considered as the optimum exposure period for chromium removal for live biomass, whereas 1.3 hours exposure time for dead biomass of A. flavus (Figs. 1 and 2). It was observed that after the optimum exposure period, chromium removal efficiency was decreased gradually with increasing contact time. The high rate of biosorption at the initial stage was due to the

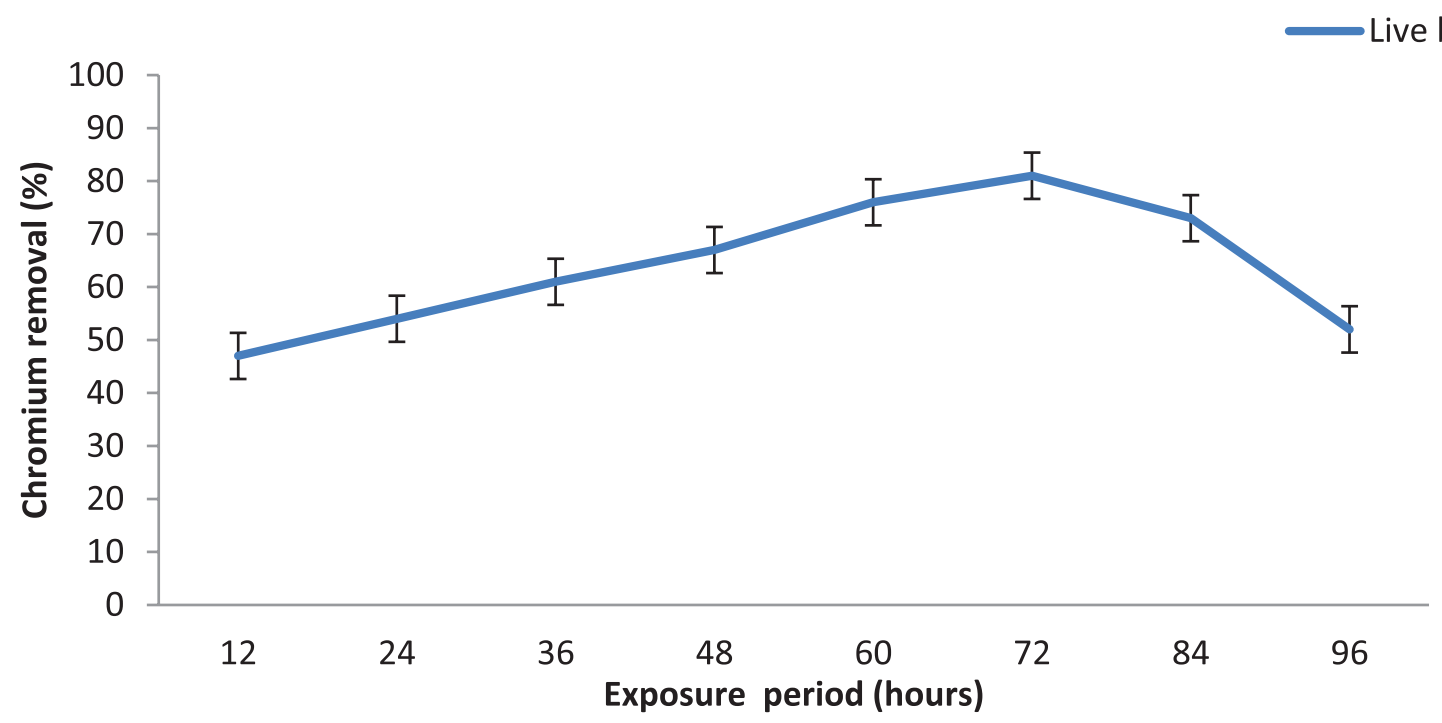

Figure 1: Exposure time effect on chromium elimination by live A. flavus. Data are mean \pm standard error of three replicates. Data were found to be significant at $p<0.05$. 


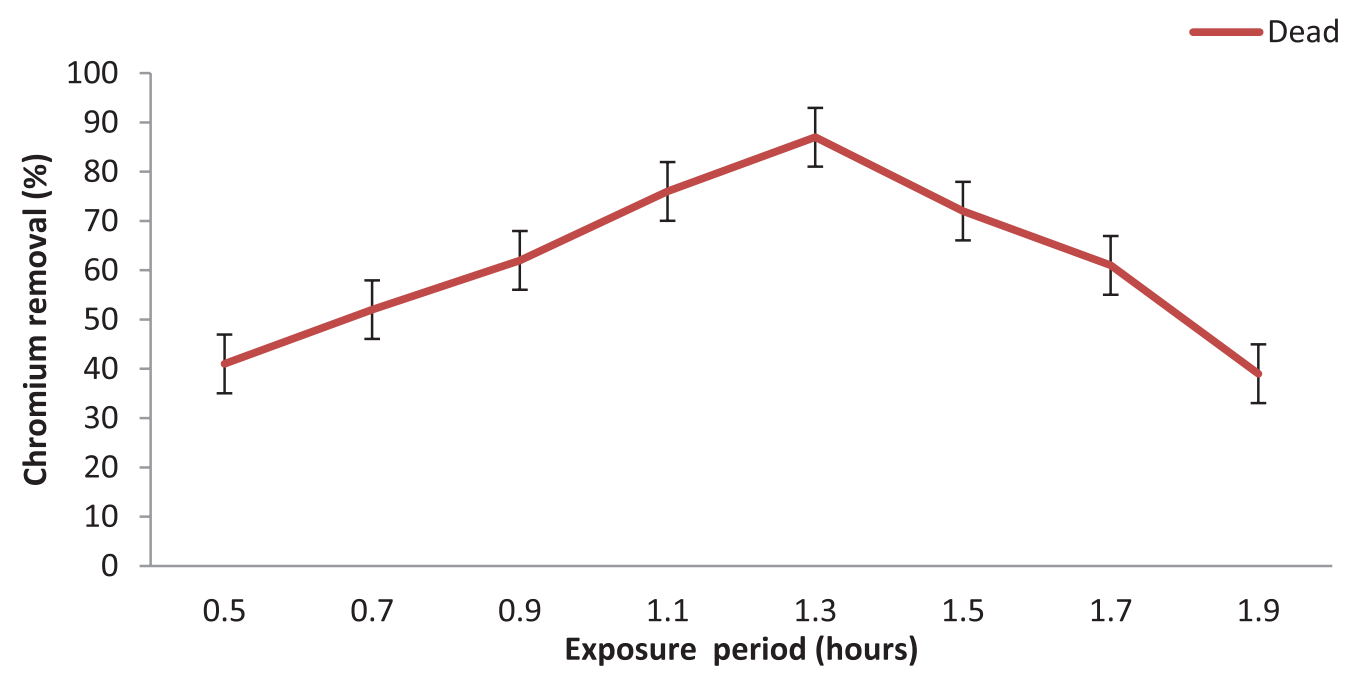

Figure 2: Exposure time effect on chromium removal by dead biomass of A. flavus. Data are mean \pm standard error of three replicates and data were found to be significant at $p<0.05$.

presence of more active centers on the surface of A. flavus. Later biosorption was merely an attachment-controlled process due to less available sorption sites.

\subsection{Effect of $\mathrm{pH}$}

Chromium removal by live and dead $A$. flavus biomass at different $\mathrm{pH}$ is shown in Figure 3. The $\mathrm{pH}$ is an important parameter in the chromium metal biosorption process. $\mathrm{Cr}$ (VI) biosorption was enhanced with escalation in $\mathrm{pH}$ from 1 to 3 for both live and dead biosorbents and reflected maximum adsorption capacity at $\mathrm{pH} 3.5$. At $\mathrm{pH} 3.5$, maximum chromium removal of $75 \%$ and $83 \%$ was observed with live and dead biomass, respectively. The reports revealed that in aqueous solution chromium is present in the form of acid chromate, dichromate, and other oxyanions. At a low $\mathrm{pH}$, acid chromate is the main form, but it gets converted into $\mathrm{CrO}_{4}{ }^{2-}$ and $\mathrm{Cr}_{2} \mathrm{O}_{7}{ }^{2-}$ with the increase in $\mathrm{pH}$.

The reduction in chromium ion removal efficiency at a high $\mathrm{pH}$ is due to competition between chromate and hydroxyl ions [29]. At low $\mathrm{pH}$, chromate ions are in $\mathrm{Cr}_{2} \mathrm{O}_{7}{ }^{2-}$ and $\mathrm{HCr}_{2} \mathrm{O}_{4}^{-}$forms and amino groups are protonated. Park et al. [30] observed that at low $\mathrm{pH}$ hexavalent chromium converts into the trivalent form.

\subsection{Effect of Initial Chromium Concentration}

Initial chromium metal concentration effect on $\mathrm{Cr}(\mathrm{VI})$ adsorption on the live and dead A. flavus biomass is shown in Figure 4. $\mathrm{Cr}$ (VI) elimination was enhanced by escalation in initial concentration of $\mathrm{Cr}$ (VI) ions. It may be due to the saturation

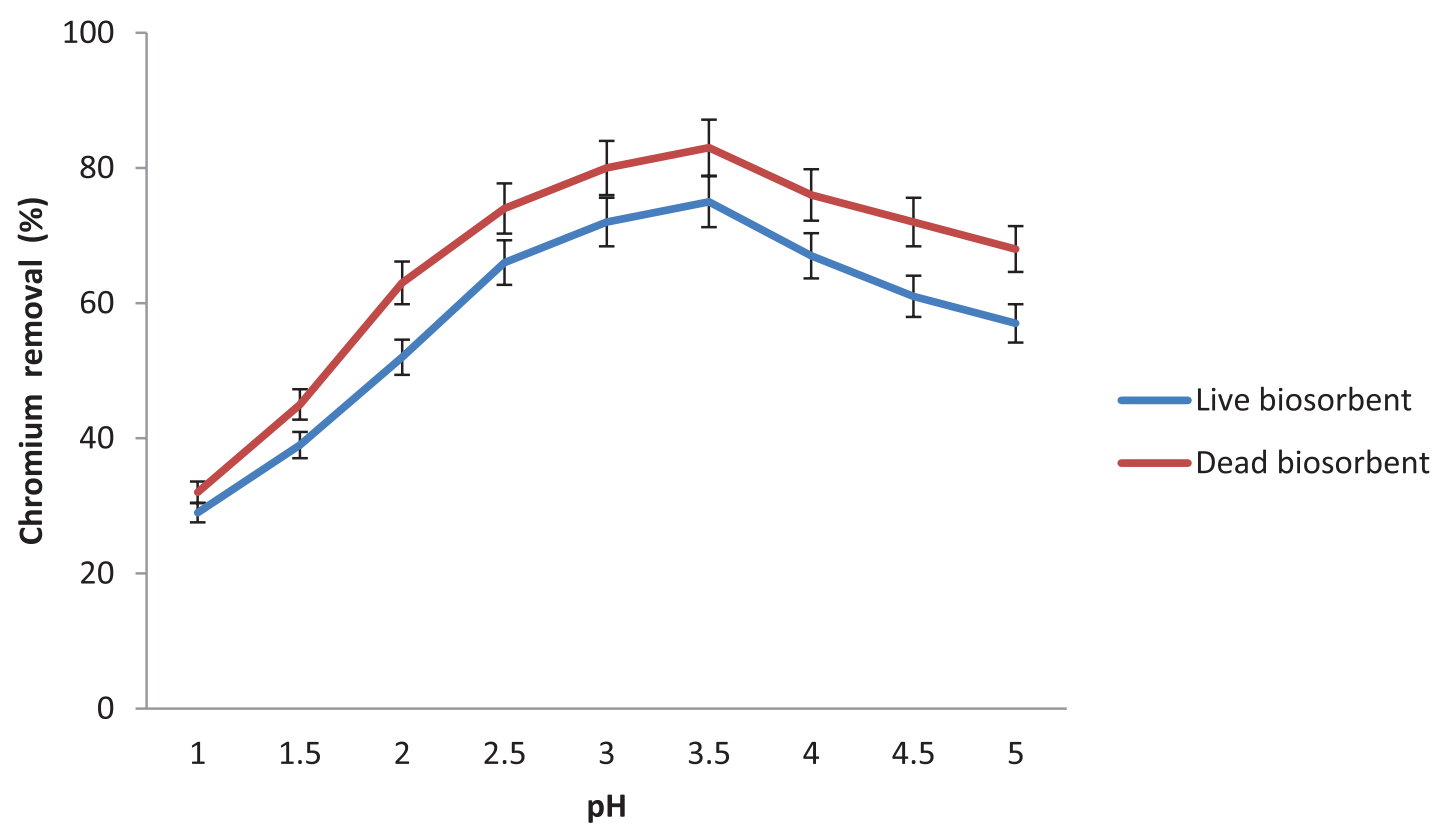

Figure 3: Biosorption of chromium by live and dead A. flavus biomass at different $\mathrm{pH}$. Data are mean \pm standard error of three replicates. Data were found to be significant at $p<0.05$. 


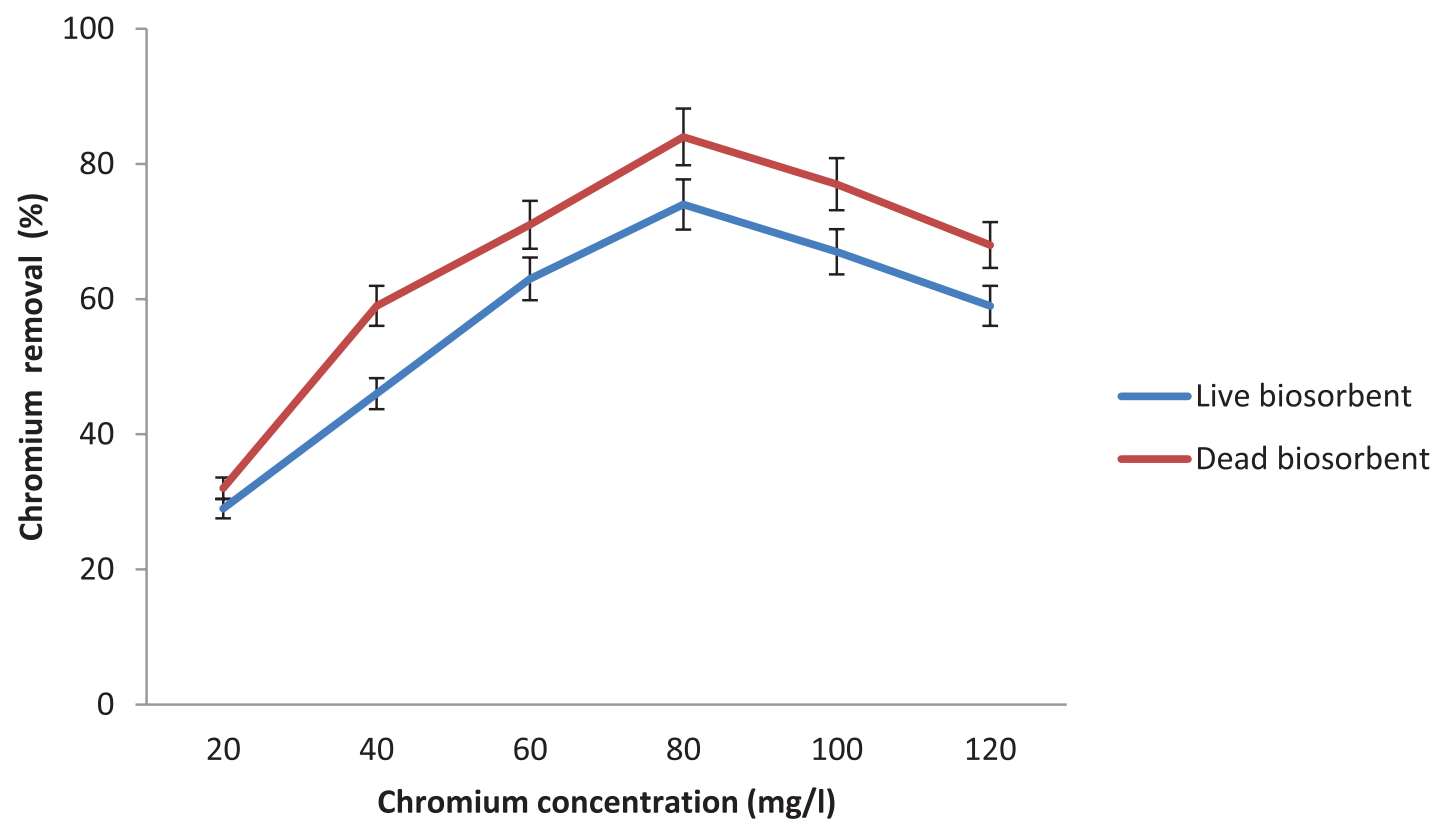

Figure 4: Impact of initial chromium concentration on chromium removal. Data are mean \pm standard error of three replicates. Data were found to be significant at $p<0.05$.

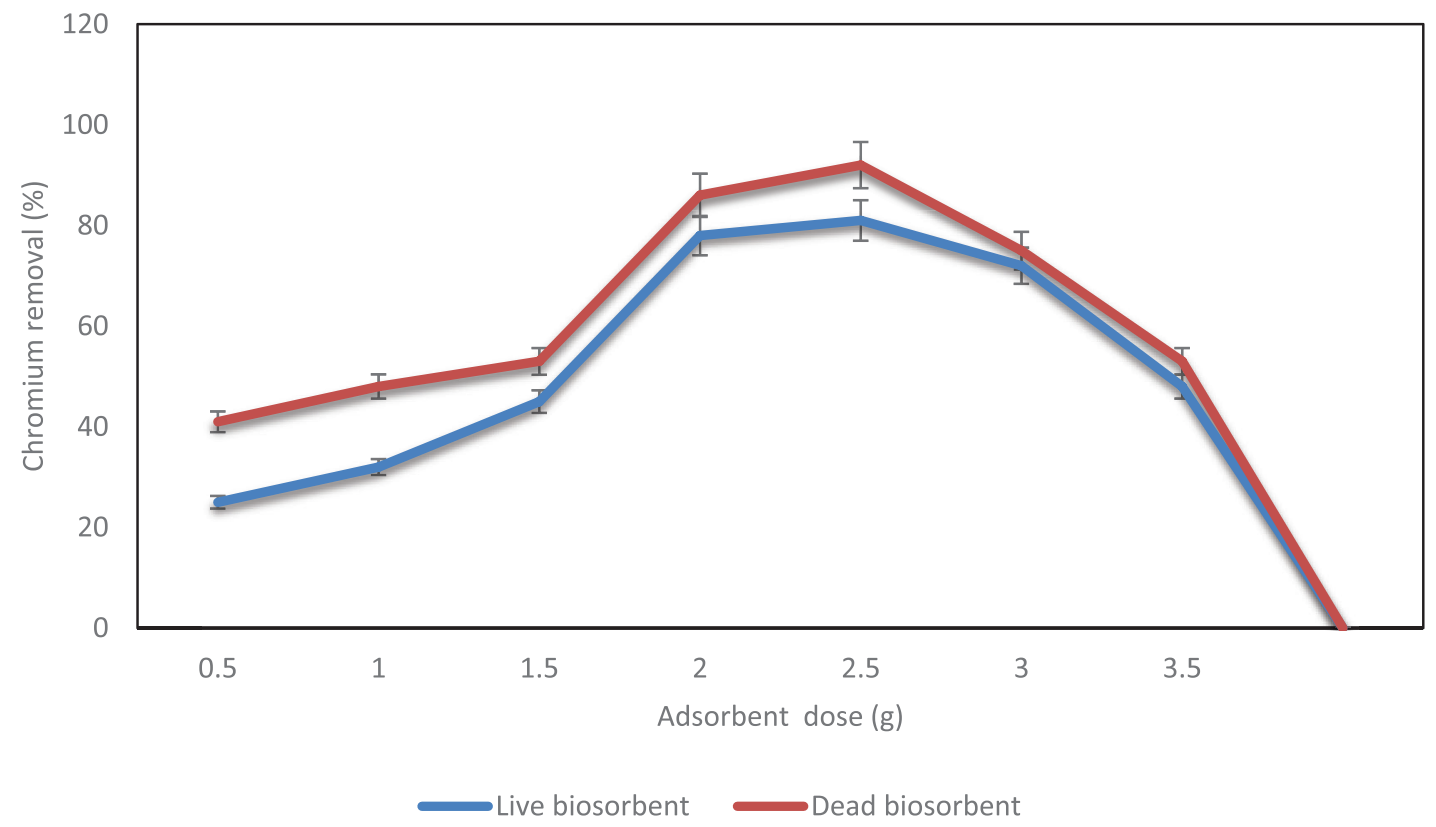

Figure 5: Effect of the adsorbent dose on chromium elimination. Data are mean \pm standard error of three replicates. Data were found to be significant at $p<0.05$.

of available active centers of fixed amount of adsorbent. The results reflected that the adsorption capacity increased with increasing initial concentration of hexavalent chromium. The metal ions provide the required driving force to exceed the mass transfer resistance of hexavalent chromium between liquid and solid adsorbent. The enhancement in initial chromium ion concentration enhanced the interaction between chromium ions in aqueous phase and biomass surface and enhanced chromium uptake by A. flavus. It might be due to the more number of active groups available for biosorption and reduction because of the increased amount of A. flavus biomass.

\subsection{Effect of Adsorbent Dose}

Different amounts of live and dead biomass of A. flavus were utilized to compare their biosorption ability for chromium. The increase in the biosorption rate of chromium was observed with an increase in the fungal biomass (Fig. 5). The biosorption capacity 


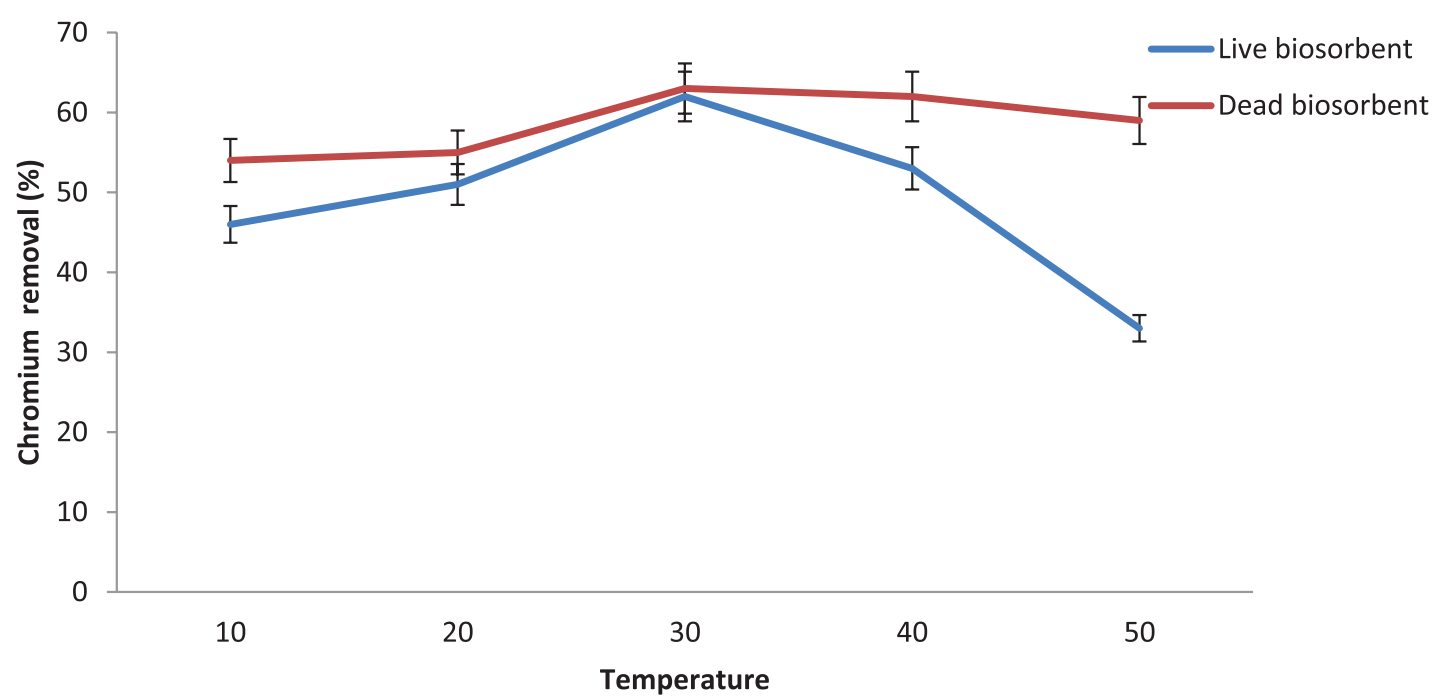

Figure 6: Effect of temperature on the chromium removal. Data are mean \pm standard error of three replicates. Data were found to be significant at $p<0.05$.

Table 1: Isotherm constants for chromium adsorption by the dead biomass of $A$. flavus.

\begin{tabular}{|c|c|c|c|c|}
\hline Isotherm & Equation & Plot & Parameters & Value \\
\hline \multirow{3}{*}{ Langmuir } & \multirow{3}{*}{$C_{\mathrm{e}} / q_{\mathrm{e}}=1 / q_{\mathrm{e}} K_{1}{ }^{`}+C_{\mathrm{e}} / q_{\mathrm{m}}$} & \multirow{3}{*}{$\begin{array}{c}C_{\mathrm{e}} / q_{\mathrm{e}} \text { versus } C_{\mathrm{e}} \text { plot showed straight line of slope } \\
1 / q_{\mathrm{m}} \text { and an intercept of } 1 /\left(K_{\mathrm{a}} q_{\mathrm{m}}\right)\end{array}$} & $q_{\mathrm{m}}(\mathrm{mg} / \mathrm{g})$ & 0.5337 \\
\hline & & & $K(1 / \mathrm{mg})$ & 147 \\
\hline & & & $R^{2}$ & 0.9485 \\
\hline Freundlich & $\begin{aligned} \log q_{\mathrm{e}} & =\log K_{\mathrm{f}}+1 / n \\
& \log C_{\mathrm{e}}\end{aligned}$ & $\begin{array}{l}K_{\mathrm{f}} \text { and } 1 / n \text { were evaluated from intercept } \\
\text { and slope of linear plot of } \operatorname{lnq}_{\mathrm{e}} \text { versus } \ln \mathrm{C}_{\mathrm{e}} \text {, } \\
\text { respectively }\end{array}$ & $\begin{array}{c}n \\
K_{\mathrm{f}}(\mathrm{mg} / \mathrm{g}) \\
R^{2}\end{array}$ & $\begin{array}{c}0.8407 \\
7.795136 \\
0.9486\end{array}$ \\
\hline
\end{tabular}

of live and dead fungi showed the following trend: $2.5>2>3>$ $3.5>1.5>1>0.5 \mathrm{~g}$. Therefore, $2.5 \mathrm{~g} / 100 \mathrm{ml}$ was considered as the optimal biosorbent dose due to its high chromium adsorption capacity. Sarikaya [31] reported that enhancement in biosorbent dosage increased Cr (VI) Agaricus campestris biosorption. The results reflected that dead biomass was effective in removal of chromium as compared to live fungal biomass (Fig. 5). It is because of more absorptive surface area and binding sites availability on dead biomass as compared to live biomass. Maximum chromium removal 92\% was observed with $2.5 \mathrm{~g} \mathrm{~A}$. flavus dead biomass, but the addition in adsorbent dose could not alter adsorption. This might be due to the absence of active sites on biomass and establishment of equilibrium between chromium on biosorbent and solution. However, after some time equilibrium biosorption capacity was reduced. It was due to the reduction in the number of effective active centers for binding of hexavalent chromium by biosorbate amount available in the medium.

\subsection{Effect of Temperature}

Temperature plays a significant role in the biosorption process. The biosorption process was increased with the increase in temperature from $10^{\circ} \mathrm{C}$ to $50^{\circ} \mathrm{C}$ with live A. flavus (Fig. 6). It shows that the interaction between chromium and A. flavus was endothermic in nature. With the rise in temperature above the optimum value, biosorption ability of live biomass declined. The dead biomass of
A. flavus did not show any significant alterations in biosorption with alteration in temperature as it could not modify functional groups with the increase in temperature.

\subsection{Adsorption Isotherm}

The adsorption isotherm model provides information on adsorption mechanism, surface property, and adsorbent capacity. This assessment helps to construct better biosorbent for future research. Langmuir isotherm deals with the homogeneous distribution of active sites on adsorbent surface and shows single molecular layer of adsorbate molecules. Freundlich isotherm model applies to heterogeneous system, and is not restricted to monolayer formation and display interaction between adsorbed molecules. It indicates that with the increase in adsorbate concentration, adsorbate amount on the adsorbent surface also enhances and sorption energy reduces with non-availability of sorption centers on adsorbent. Hence, isotherm data of chromium adsorption on A. flavus biomass was assessed by using Langmuir and Freundlich models (Table 1).

In this investigation, Freundlich isotherm showed better fitting model as compared to Langmuir due to high correlation coefficient $\left(R^{2}=0.9486\right)$. After calculation by the equation, Langmuir constants reflected the following values: $q_{\mathrm{m}}=0.5337 \mathrm{mg} / \mathrm{g}$, $k=147 \mathrm{mg}^{-1}$, and $R^{2}=0.9485$, and Freundlich constants were $K_{\mathrm{f}}=7.795136$ and $n=0.8407$ (Fig. 7a and b). 

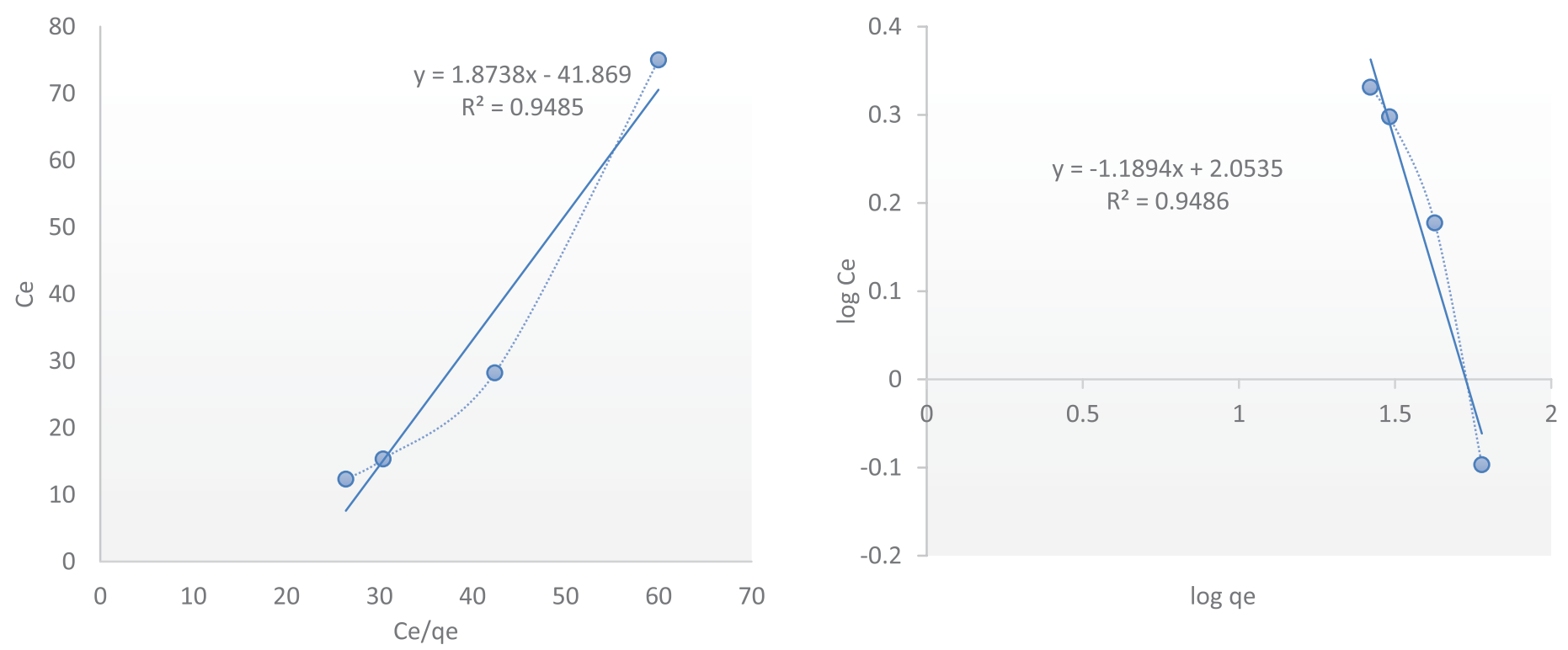

Figure 7: (A). Langmuir isotherm for chromium adsorption by the dead biomass of A. flavus. (B). Freundlich isotherm for chromium adsorption by the dead biomass of A. flavus.

Table 2: Effect of chromium before and after treatment with live and dead biomass of $A$. flavus on germination and growth parameters of $V$. radiata.

\begin{tabular}{ccccc} 
Treatment & $\begin{array}{c}\text { Seed germination } \\
(\mathbf{\%})\end{array}$ & $\begin{array}{c}\text { Radicle } \\
\text { length }(\mathbf{c m s})\end{array}$ & $\begin{array}{c}\text { Plumule length } \\
(\mathbf{c m s})\end{array}$ & Vigour index \\
Control & $96.59 \pm 0.74^{\mathrm{a}}$ & $3.1 \pm 0.22^{\mathrm{a}}$ & $8.2 \pm 0.72^{\mathrm{a}}$ & 10,901 \\
Chromium (VI) & $23.43 \pm 0.66^{\mathrm{c}}$ & $0.34 \pm 0.01^{\mathrm{c}}$ & $2.8 \pm 0.25^{\mathrm{c}}$ & 738.21 \\
$\begin{array}{c}\text { Chromium solution treated with live } \\
\text { fungal biomass }\end{array}$ & $72.85 \pm 0.67^{\mathrm{b}}$ & $1.8 \pm 0.09^{\mathrm{b}}$ & $5.4 \pm 0.42^{\mathrm{b}}$ & 5,245 \\
$\begin{array}{c}\text { Chromium solution treated with dead } \\
\text { fungal biomass }\end{array}$ & $92.63 \pm 0.73^{\mathrm{a}}$ & $2.7 \pm 0.18^{\mathrm{a}}$ & $7.6 \pm 0.51^{\mathrm{a}}$ & 9,539 \\
\hline $\begin{array}{c}\text { Data are mean } \pm \text { standard error of three independent experiments. Values followed by different letters show a significant difference at } \\
p<0.05 \text { between treatment according to analysis of variance and Duncan's Multiple Range Test (DMRT). }\end{array}$
\end{tabular}

\subsection{Phytotoxicity Study}

The phytotoxicity test was conducted to check the suitability of chromium-treated water for irrigation purposes. The effect of chromium metal ions and treated chromium solution with live and dead biosorbent of $A$. flavus was compared on the growth parameters of $V$. radiata. Several changes were observed under different treatment for seed germination and morphological properties of mung bean seeds (Table 2). Maximum 97\% seed germination was reported in control and chromium metal-treated seeds showed only $23 \%$ seed germination. The radicle and plumule length were 3.1 and $8.2 \mathrm{~cm}$ in control which were significantly reduced to 0.34 and $2.8 \mathrm{~cm}$ in chromium metal solution, respectively. The significant increase $211.19 \%$ and $295.68 \%$ in mung bean seed germination was reported with chromium solution treated with live and dead fungal biomass, respectively, over chromium metal solution. The dead fungal biomass-treated chromium solution showed significant increase in radicle and plumule length as compared to live fungal biomass treated chromium solution. Vigor index of mung bean seeds showed trend: control $>$ chromium solution treated with dead biosorbent $>$ chromium solution treated with live biosorbent solution $>$ chromium.

Chromium accumulation in crop fields shows reduction in plant growth and development process at cellular or genetic level as chromium incited toxicity enhances production of free radicals [32]. Tomko et al. [33] reported 90\%-95\% removal efficiencies of copper, aluminum, and antimony from their respective aqueous solution by fungal biomass. Javaid et al. [34] used pretreated Aspergillus niger as adsorbent for copper and nickel metals removal. Rao and Bhargavi [35] observed that pretreated fungal biomass can be used as biosorbent for the removal of nickel and lead. Mali et al. [36] found that A. flavus can be applied as an adsorbent for removal of zinc metal. The biosorption of lead was reported by Aspergillus terreus [37] and Aspergillus versicolor [38]. Application of Bacillus species for lead adsorption was reported by Garcia et al. [39]. Mahish et al. [40] found that Penicillium oxalicum showed 90\% lead adsorption capacity. 
Table 3: Comparison of chromium removal efficiency by various biosorbents.

\begin{tabular}{cccc} 
Metal & Biosorbent & $\begin{array}{c}\text { Adsorption } \\
\text { capacity } \\
(\mathbf{m g} / \mathbf{g})\end{array}$ & References \\
& Agaricus campestris & 56.21 & Sarikaya [31] \\
& Sugarcane bagasse & 4.4 & Garg et al. [41] \\
Hexavalent & Jatropha oil cake & 4.8 & Garg et al. [41] \\
chromium & Maize corncob & 3 & Garg et al. [41] \\
& Aspergillus niger & 11.79 & Mondal et al. [22] \\
& Aspergillus flavus & 0.53 & This study \\
\hline
\end{tabular}

\subsection{Performance of A. flavus as Compared to Other Adsorbents}

The efficiency of $A$. flavus for chromium removal was compared with other adsorbents and is given in Table 3. Chromium removal efficiency is in consonance with previous findings, showing that chromium can be easily adsorbed on A. flavus biomass. It indicates that fungal biomass can be used as costeffective and environmentally benign biosorbent for chromium removal.

To the best of our knowledge, only few reports have compared live and dead biosorbent capacity for metal removal from aqueous solution or wastewater system $[38,42]$. The biosorption of chromium metal with live and dead biomass of $A$. flavus has not been reported earlier. Khadivinia et al. [43] found that dead biosorbents can be used as a better alternative as compared to live biomass. Paul et al. [44] found that heat treatment to bacterial biosorbent enhanced their capacity to adsorb metal ions, and it may be because of cell wall degradation and exposure of binding sites for metal ions. Cheng et al. [45] reported that dead biosorbents have many benefits as compared to live biomass like more efficiency, no need of nutrients, less sludge production, and not expensive. The live biomass can transport adsorbed heavy metals inside the cells and converts metal ions into less toxic forms [46]. The live biosorbents can easily eliminate heavy metals even at very low concentrations [47]. The live and dead fungi have been recognized as a promising low-cost biosorbents for the removal of heavy metal ions due to their advantages [48]; hence, it needs to be explored further to take maximum advantage for treatment of industrial wastewater.

\section{CONCLUSION}

The present investigation has revealed that both live and dead biomasses of $A$. flavus were effective in removing hexavalent chromium from aqueous solution. The non-viable biomass reflected higher metal biosorption capacity as compared to the live biomass. Equilibrium data were fitted well with the Freundlich adsorption isotherm. Hence, it can be concluded from the findings of the present paper that hexavalent chromium can be efficiently removed from aqueous solution by using both live and dead biomasses of $A$. flavus. Further investigations are required for optimization of environmental parameters for its application in effluent treatment at contaminated sites under natural conditions.

\section{ACKNOWLEDGMENTS}

The author is grateful to Amity Institute of Biotechnology, Amity University, Noida, for providing laboratory facilities for the study.

\section{CONFLICT OF INTEREST}

There is no conflict of interest.

\section{ETHICAL APPROVAL}

Not applicable.

\section{AUTHORS' CONTRIBUTION}

R.T. Kapoor carried out the experiments and prepared the manuscript.

\section{REFERENCES}

1. Ali H, Khan E. What are heavy metals? Long-standing controversy over the scientific use of the term heavy metals proposal of a comprehensive definition. Toxicol Environ Chem 2018;100(1-2):6-19.

2. Prasad S, Yadav KK, Kumar S, Gupta N, Cabral-Pinto MMS, Rezania $\mathrm{S}$, et al. Chromium contamination and effect on environmental health and its remediation: a sustainable approaches. J Environ Manage 2021;285:112174.

3. Chowdhury S, Mazumder MAJ, Al-Attas O, Husain T. Heavy metals in drinking water: occurrences, implications, and future needs in developing countries. Sci Total Environ 2016;569-570:476-88.

4. Hong YJ, Liao W, Yan ZF, Bai YC, Feng CL, Xu ZX, et al. Progress in the research of the toxicity effect mechanisms of heavy metals on freshwater organisms and their water quality criteria in China. Hindawi J Chem 2020;2020:1-12. Article ID 9010348.

5. Schiavon M, Pilon-Smits E, Wirtz M, Hell R, Malagoli M. Interactions between chromium and sulfur metabolism in Brassica juncea. J Environ Qual 2008;37:1536-45.

6. Pushkar B, Sevak P, Parab S, Nilkanth N. Chromium pollution and its bioremediation mechanisms in bacteria: a review. J Environ Manage 2021;287:112279.

7. Wakeel A, Xu M, Gan Y. Chromium-induced reactive oxygen species accumulation by altering the enzymatic antioxidant system and associated cytotoxic, genotoxic, ultrastructural and photosynthetic changes in plants. Int J Mol Sci 2020;21:728.

8. Ashraf A, Bibi I, Niazi NK, Ok YS, Murtaza G, Shahid M, et al. Chromium(VI) sorption efficiency of acid-activated banana peel over organo-montmorillonite in aqueous solutions. Int $\mathrm{J}$ Phytoremediat 2017;19:605-13.

9. Sultana MY, Akratos CS, Pavlou S, Vayenas DV. Chromium removal in constructed wetlands: a review. Int Biodeterior Biodegrad 2014;96:181-90.

10. Des Marias TL, Costa M. Mechanisms of chromium-induced toxicity. Curr Opinion Toxicol 2019;14:1-7.

11. Desai C, Jain K, Madamwar D. Evaluation of in vitro Cr (VI) reduction potential in cytosolic extracts of three indigenous Bacillus sp. isolated from $\mathrm{Cr}$ (VI) polluted industrial landfill. Biores Technol 2008;99:6059-69.

12. Salnikow K, Zhitkovich A. Genetic and epigenetic mechanisms in metal carcinogenesis and cocarcinogenesis: nickel, arsenic and chromium. Chem Res Toxicol 2008;21:28-44.

13. Domingo-Relloso A, Grau-Perez M, Galan-Chilet I, Garrido-Martinez MJ, Tormos C, Navas-Acien A, Gomez-Ariza JL, et al. Urinary metals and metal mixtures and oxidative stress biomarkers in an adult population from Spain: the Hortega study. Environ Int 2019;123:171-80.

14. Rager JE, Suh M, Chappell GA, Thompson CM, Proctor DM. Review of transcriptomic responses to hexavalent chromium exposure in lung 
cells supports a role of epigenetic mediators in carcinogenesis. Toxicol Lett 2019;305:40-50.

15. Mamatha M, Aravinda HB, Puttaiah ET, Manjappa S. Adsorption of ferrous and ferric ions in aqueous and industrial effluent onto Pongamia pinnata tree bark. Int J Chem Biomol Metall Mater Sci Eng 2012;6(7):49-57.

16. Chauhan J, Yadav VK, Saini I, Jha RK, Tanwar A, Kaushik P. Effect of fungal pretreatment on Solanum nigrum L. leaves biomass aimed at the bioadsorption of heavy metals. Ind J Tradit Knowl 2020a;19(4):832-8.

17. Atkinson BW, Bux F, Kasan HC. Considerations for application of biosorption technology to remediate metal-contaminated industrial effluents. Water S A 1998;24(2):129-35.

18. Chauhan J, Yadav VK, Sahu AP, Jha RK, Kaushik P. Biosorption potential of alkali pretreated fungal biomass for the removal and detoxification of lead metal ions. J Sci Ind Res 2020b;79(07):636-9.

19. Ahluwalia SS, Goyal D. Microbial and plant derived biomass for removal of heavy metals from wastewater. Bioresour Technol 2007;98(12):2243-57.

20. Sarma GVS, Rani KS, Chandra KS, Babu BK, Ramesh KV. Potential removal of phenol using modified laterite adsorbent. Ind J Biochem Biophys 2020;57(5):613-9.

21. Saad AM, Moataza MS, Hassan HM, Ibrahim NA, El-Hadedy DE, Ibrahim EI, et al. Optimization study for $\beta$-mannanase production from locust bean gum by a local Aspergillus tamarii NRC 3 isolate. Res J Pharm Biol Chem Sci 2016;7(6):2597-609.

22. Mondal NK, Samanta A, Dutta S, Chattoraj S. Optimization of Cr (VI) biosorption onto Aspergillus niger using 3-level Box-Behnken design: equilibrium, kinetic, thermodynamic and regeneration studies. J Genet Eng Biotechnol 2017;15:151-60.

23. Saad AM. Factors affecting cobalt uptake by cobalt-trained Mucor rouxii NRRL 1894 biomass. Eur J Biotechnol Biosci 2015;3(3):1-6.

24. Clesceri LS, Greenberg AE, Eaton AD. Standard methods for the examination of water and wastewater. 20th edition, American Public Health Association, Washington DC, 1998.

25. Bharathi KS, Ramesh SPT. Fixed-bed column studies on biosorption of crystal violet from aqueous solution by Citrullus lanatus rind and Cyperus rotundus. Appl Water Sci 2013;3:673-87.

26. Ng C, Losso JN, Marshall WE, Rao RM. Freundlich adsorption isotherms of agricultural by-product-based powdered activated carbons in a geosmin-water system. Bioresour Technol 2002;85:131-5.

27. ISTA, International rules for seed testing. International Seed Testing Association. ISTA Secretariat, Bassersdorf, Switzerland, 2008.

28. Abdul Baki AA, Anderson JD. Vigor determination in soybean seed by multiple criteria. Crop Sci 1973;13:630-3.

29. Sugashini S, Begum KMMS. Optimization using central composite design for the biosorption of $\mathrm{Cr}(\mathrm{VI})$ ions by cross linked chitosan carbonized rice husk (CCACR). Clean Techn Environ Policy 2013;15:293-302.

30. Park D, Yun YS, Jo JH, Park JM. Mechanism of hexavalent chromium removal by dead fungal biomass of Aspergillus niger. Water Res 2005;39(4):533-40.

31. Sarikaya AG. Kinetic and thermodynamic studies of the biosorption of $\mathrm{Cr}(\mathrm{VI})$ in aqueous solutions by Agaricus campestris. Environ Technol 2019;42:1-9; doi:10.1080/09593330.2019.1620867

32. Wakeel A, Ali I, Wu M, Kkan AR, Jan M, Ali A, et al. Ethylene mediates dichromate-induced oxidative stress and regulation of the enzymatic antioxidant system-related transcriptome in Arabidopsis thaliana. Environ Exp Bot 2019;161:166-79.

33. Tomko J, Backor MS, Tofko M. Biosorption of heavy metals by dry fungi biomass. Acta Metall Slovaka 2006;12:447-51.

34. Javaid A, Bajwa R, Manzoor T. Biosorption of heavy metals by pretreated biomass of Aspergillus niger. Pak J Bot 2011;43(1):419-25.
35. Rao PR, Bhargavi C. Studies on biosorption of heavy metals using pretreated biomass of fungal species. Int $\mathrm{J}$ Chem Chem Eng 2013;3(3):171-80.

36. Mali A, Pandit V, Majumder DR. Biosorption and desorption of zinc and nickel from wastewater by using dead fungal biomass of Aspergillus flavus, Int J Tech Res Appl 2014;2(6):42-6.

37. Sun YM, Horng CY, Chang FL, Cheng LC, Tian WX. Biosorption of lead, mercury and cadmium ions by Aspergillus terreus immobilized in a natural matrix. Pol J Microbiol 2010;59(1):37-44.

38. Soleimani N, Mohammadian FM, Ramazani A, Mehrasbi MR Application of live, dead, and dried biomasses of Aspergillus versicolor for cadmium biotreatment. J Hum Environ Health Promot 2016;1(2):87-98.

39. Garcia R, Campos J, Cruz JA, Calderón ME, Raynal ME, Buitrón G. Biosorption of $\mathrm{Cd}, \mathrm{Cr}, \mathrm{Mn}$, and $\mathrm{Pb}$ from aqueous solutions by Bacillus sp. strains isolated from industrial waste activate sludge. TIP Revista Especializada en Ciencias Químico-Biológicas 2016;19(1):5-14.

40. Mahish PK, Tiwari KL, Jadhav SK. Biosorption of lead by biomass of resistant Penicillium oxalicum isolated from industrial effluent. J Appl Sci 2018;18(1):41-7.

41. Garg UK, Kaur MP, Garg VK, Sud D. Removal of hexavalent chromium from aqueous solution by agricultural waste biomass. J Hazard Mater 2007;140:60-8.

42. Hu X, Cao J, Yang H, Li D, Qiao Y, Zhao J. Pb2+ biosorption from aqueous solutions by live and dead biosorbents of the hydrocarbon-degrading strain Rhodococcus sp. HX-2. PLoS One 2020;15(1):e0226557.

43. Khadivinia E, Sharafi H, Hadi F, Zahiri HS. Cadmium biosorption by a glyphosate-degrading bacterium, a novel biosorbent isolated from pesticide-contaminated agricultural soils. J Ind Eng Chem 2014;20(6):430-10

44. Paul ML, Samuel J, Chandrasekaran N, Mukherjee A. Comparative kinetics, equilibrium, thermodynamic and mechanistic studies on biosorption of hexavalent chromium by live and heat killed biosorbent of Acinetobacter junii VITSUKMW2, an indigenous chromite mine isolate. Chem Eng J 2012;187:104-13.

45. Cheng $\mathrm{Y}$, Yang $\mathrm{C}, \mathrm{He} \mathrm{H}$, Zeng G. Biosorption of $\mathrm{Pb}$ (II) ions from aqueous solutions by waste biosorbent from biotrickling filters: kinetics, isotherms, and thermodynamics. J Environ Eng 2015;142(9):C4015001.

46. Yin K, Wang Q, Lv M, Chen L. Microorganism remediation strategies towards heavy metals. Chem Eng J 2018;1553:1563.

47. Hlihor RM, Figueiredo H, Tavares T, Gavrilescu M. Biosorption potential of dead and living Arthrobacter viscosus biosorbent in the removal of $\mathrm{Cr}$ (VI): batch and column studies. Process Saf Environ Protect 2017;108:44-56.

48. Ayele A, Haile S, Alemu D, Kamaraj M. Comparative utilization of dead and live fungal biomass for the removal of heavy metal: a concise review. Sci World J 2021;2021:1-10. Article ID 5588111.

How to cite this article:

Kapoor RT. Evaluation of the biosorption potential of Aspergillus flavus biomass for removal of chromium (VI) from an aqueous solution. J Appl Biol Biotech 2022; 10(02):59-67. 